\title{
The incidence of collagen-associated adverse events in pediatric population with the use of fluoroquinolones: a nationwide cohort study in Taiwan
}

Pei-Han $\mathrm{Yu}^{1,2+}$, Chih-Fen Hu ${ }^{3+}$, Jen-Wei Liu ${ }^{2,4}$, Chi-Hsiang Chung ${ }^{5}$, Yong-Chen Chen ${ }^{6,7}$, Chien-An Sun ${ }^{7,8}$ and Wu-Chien Chien ${ }^{5,9,10^{*}}$ (D)

\begin{abstract}
Background: To evaluate the safety of using fluoroquinolones in pediatric population in Taiwan.

Methods: Patients aged 0 18 years old with fluoroquinolones prescriptions $\geq 5$ consecutive days during year 2000 to 2013 were selected from the National Health Insurance Research Database, 4-time case number were selected as controls. We evaluated the patient's outcome after the use of fluoroquinolones by reviewing a newly diagnosis of the following collagen-associated adverse events by International Classification of Diseases, Ninth Revision, Clinical Modification codes, covering tendons rupture, retinal detachments, gastrointestinal tract perforation, aortic aneurysm or dissection.

Results: Of the enrolled patients ( $n=167,105)$, collagen-associated adverse effects developed in 85 cases $(0.051 \%)$ in 6-month tracking, including $0.051 \%$ in the fluoroquinolones study cohort $(17$ in 33,421) and $0.051 \%$ (68 in 133, 684 ) in the fluoroquinolones free comparison cohort. The crude hazard ratio for collagen-associated adverse events in the fluoroquinolones group was $0.997(0.586-1.696 ; p=0.990)$. After adjusting for age, sex, catastrophic illness, low-income household, seasons, levels of urbanization, and healthcare, the corrected hazard ratio in 6-month tracking with FQs was 1.330 (95\% Cl; 0.778-2.276; $p=0.255)$.

Conclusions: There is no significant difference of collagen-associated adverse effects between fluoroquinolones group and fluoroquinolones free group from our data. We propose that fluoroquinolones for pediatric population in clinical practice may be not so harmful as previous references reported.
\end{abstract}

Keywords: Fluoroquinolones, Pediatric patients, Collagen-associated adverse effects, Prescription safety issue

\section{Background}

Fluoroquinolones (FQs) are effective antimicrobial agents by directly inhibiting the process of bacterial DNA synthesis. With the broad-spectrum antibacterial coverage, they are widely used in bacterial infections, like acute bacterial sinusitis, acute bacterial exacerbations of chronic bronchitis, and uncomplicated urinary tract

\footnotetext{
* Correspondence: chienwu@ndmctsgh.edu.tw

${ }^{\dagger}$ Pei-Han Yu and Chih-Fen Hu contributed equally to this work.

${ }^{5}$ School of Public Health, National Defense Medical Center, Taipei 11490, Taiwan

${ }^{9}$ Graduate Institute of Life Sciences, National Defense Medical Center, Taipe

11490, Taiwan

Full list of author information is available at the end of the article
}

infections for adults. In addition to the strength of broad-spectrum antibacterial coverage, other advantages, such as high oral bioavailability, large volume of distribution, ideal tissue penetration and long-lasting medicine, make FQs a favorable choice in treating infectious diseases $[1,2]$.

However, FQs are not the first choice in clinical guideline for treating infectious diseases, since they have been reported to be associated with collagen degradation, which may lead to severe and detrimental adverse effects like tendon ruptures, retinal detachments, gastrointestinal tract perforation, even aortic aneurysms in adults [3-7]. FQs were previously found to cause apoptotic

(c) The Author(s). 2020 Open Access This article is distributed under the terms of the Creative Commons Attribution 4.0 International License (http://creativecommons.org/licenses/by/4.0/), which permits unrestricted use, distribution, and reproduction in any medium, provided you give appropriate credit to the original author(s) and the source, provide a link to the Creative Commons license, and indicate if changes were made. The Creative Commons Public Domain Dedication waiver (http://creativecommons.org/publicdomain/zero/1.0/) applies to the data made available in this article, unless otherwise stated. 
changes in extracellular matrix and significantly decrease collagen type I and the $\beta 1$-integrin receptors [8]. Collagen defects-related tissue damages are found not only in tendons, but also tissues composed of collagen, such as aortic wall, gastrointestinal (GI) tract, and retina [5, 9, 10]. All of these findings attribute to the cause of collagen-associated adverse effects. To alarm the risks of adverse effects of FQs, the U.S. FDA declared several warnings containing potential tendinitis, tendon ruptures, and even irreversible peripheral neuropathy $[11,12]$.

On the other hand, the original toxicological studies with quinolones documented the cartilage injury in weight-bearing joints in canine puppies [13]. With the concern of potential negative impacts on musculoskeletal development in growing children, systemically administered FQs are not recommended for routine use in children younger than 18 years old except for some complicated and complex infectious diseases cases [14]. To follow the clinical guidelines and recommendations in treating infectious diseases in children [15], the physicians tend to reserve the prescriptions of FQs as the last line antibiotics to tackle with fulminant and invasive bacterial infections at hospitals in Taiwan.

Although the use of FQs to treat bacterial infection in pediatric population has been decreasing with time, there is still a small pediatric group who needs FQs for treating serious and multiple drug-resistant bacterial infections rising in the community [16, 17]. For this reason, it is urgently needed to evaluate the safety of FQs in clinical use. After reviewing the literatures, we found that most of the study subjects for adverse effects of FQs were older than 18-year old patients $[3-5,7,18]$. By contrast, there are still a few publications reporting benefits for using FQs in children [19, 20]. Since the lack of sufficient evidence-based articles found in pediatric population, the purpose of our study is to investigate the safety issue of FQs-induced collagen-associated adverse effects at the young age group.

\section{Methods}

\section{Data sources}

We performed a cohort study by using the National Health Insurance Research Database (NHIRD) of Taiwan. The National Health Insurance (NHI) system of Taiwan covers more than $99.6 \%$ of the Taiwanese population [21]. This database is representative of the population in Taiwan, and always used in generating evidence to support clinical decisions or healthcare policy-making [22]. All data from primary outpatient departments and inpatient hospital care settings after year 2000 were included in this database. This longitudinal health insurance database in year 2000-2013 in Taiwan was collected by randomly selecting individuals from the registry for beneficiaries of the NHI program. It contains complete outpatient and inpatient electronic claim records, individual diagnoses, procedures, and medicine prescription. This database is commonly used in several population-based studies and pharmacoepidemiologic research in Taiwan. (https://nhird.nhri.org.tw/).

\section{Medication exposure}

In this study, medication exposure was defined as receiving FQs in either oral or intravenous form of the following active compounds including ciprofloxacin, levofloxacin, ofloxacin, gemifloxacin, norfloxacin, and moxifloxacin. Topical or external form of prescription was not included. The prescription period was equal to (or longer than) five consecutive days to correspond with the inclusion criteria.

\section{Inclusion and exclusion criteria}

We utilized data between year 2000 and 2013 from NHIRD of a sub-dataset, longitudinal health insurance database $(n=989,753)$. All patients aged $0 \sim 18$ years old with FQs prescriptions $\geq 5$ consecutive days after January 1, 2000 were selected and included into this cohort. The total cases were 33,537 individuals included. The patients without tracking information $(n=22)$, with missing data on gender $(n=7)$, those who ever received FQs before index date $(n=65)$, with collagenassociated adverse events, and primary or secondary collagen diseases prior to enrollment $(n=4)$ were excluded. Also, we excluded cases with the diagnosis of appendicitis (International Classification of Diseases, Ninth Revision, Clinical Modification (ICD-9-CM code): 540-543), peritonitis (ICD-9-CM code: 567), and typhoid fever (ICD-9-CM code: 002) $(n=18)$ because the symptoms of these diseases are similar to one of the primary outcomes (GI perforation) in this study [4]. The total excluded cases were 116 individuals. Overall, the final enrolled cases with the use of FQs were 33,421 individuals. Propensity score matching was used for selecting control group, and 4-fold case number were selected (Fig. 1).

\section{Outcome}

All of the diseases and adverse effects were defined by ICD-9-CM. The outcome was evaluated and defined by the newly diagnosis of the collagen-associated adverse events, including tendons rupture (727.6), retinal detachments (361.0), gastric perforation (531.1, 531.2, 531.5, 531.6, 532.1, 532.2, 532.5, 532.6, 533.1, 533.2, 533.5, $533.6,534.1,534.2,534.5$, and 534.6), small or large intestinal perforation (569.83) [4], aortic aneurysm (441.1, 441.2, 441.3, 441.4, 441.5, 441.6, 441.7, and 441.9), and aortic dissection (441.0, 441.00, 441.01, 441.02, and 441.03) [18]. 


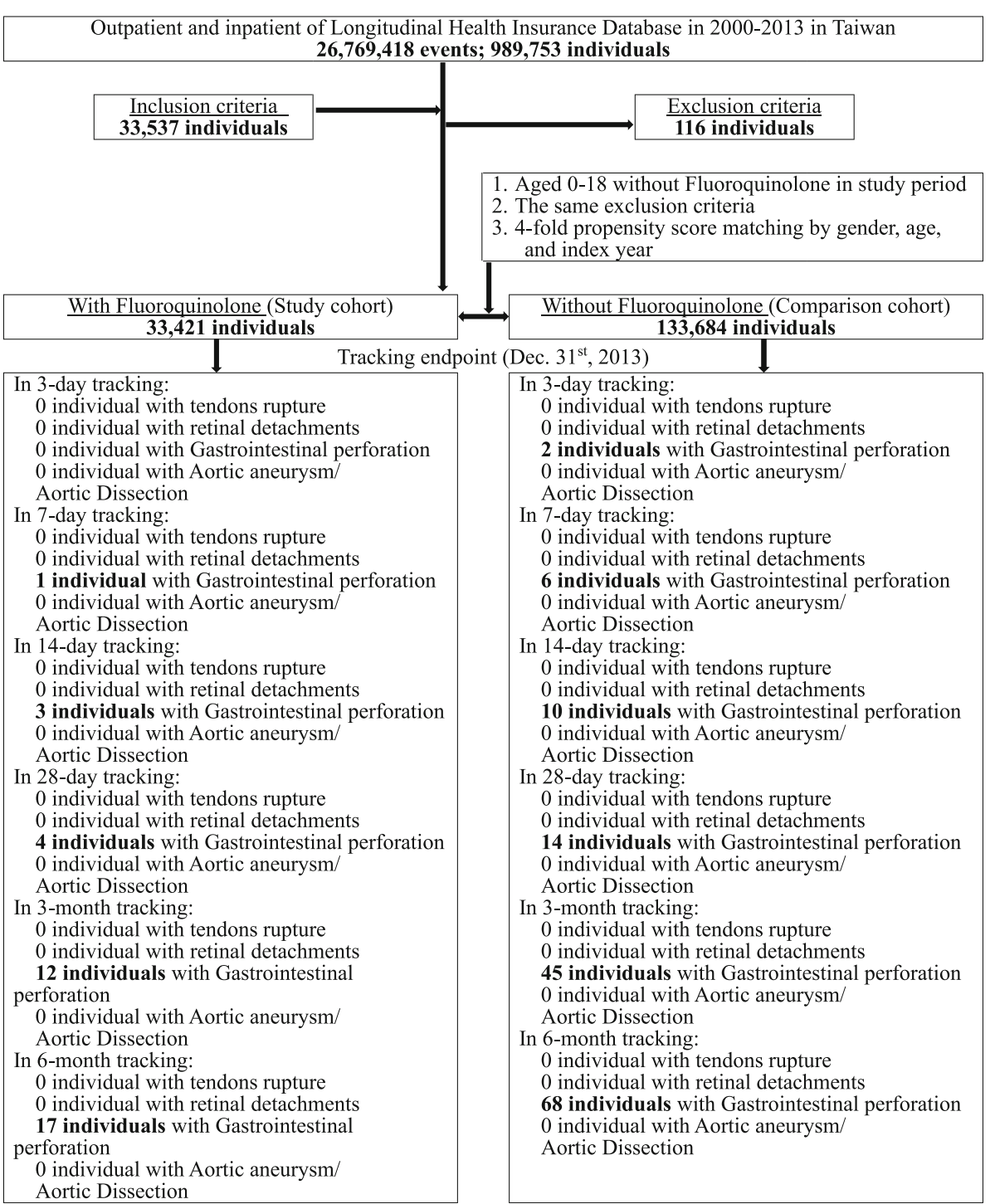

Fig. 1 The flowchart of study sample selections

\section{Covariates}

In order to be as comprehensive as possible in adjusting for factors that might confound the studied association, we identified several covariates such as catastrophic illness to adjust the baseline health conditions of selected patients, and low-income household for individual financial conditions. On the other hand, medicine such as nonsteroidal anti-inflammatory drugs (NSAIDs) and steroid are both well-known for causing gastrointestinal mucosal damage [23, 24]. Since these two medicines were commonly used in our study population, we added these two items as covariates to eliminate the interference of outcome interpretation. Moreover, we also adjusted for selected other variables such as seasons, levels of urbanization, healthcare, and comorbidities (including cerebrovascular accident, diabetes Mellitus, hypertension, hyperlipidemia) [25-27] for minimizing potential biases.

\section{Statistical analysis}

Statistical analyses were performed using Chi-square/ Fisher exact test on category variables and t-test on continuous variables. Characteristics and outcome events of cohort patients for the FQs and FQs free groups were reported as number and percentage, mean and standard deviation, as appropriate. The Kaplan-Meier analysis and log-rank test were used for calculating the cumulative incidence rates of collagen-associated adverse events between FQs group and FQs-free group. The multivariable Cox proportional hazard model was used to estimate the hazard ratio (HR) of collagen-associated adverse events associated with the use of FQs. Our 
definition of significant level was 0.05 to detect differences in collagen-associated adverse events between FQs group and FQs-free group. All analyses were performed with SPSS version 22.

\section{Results}

This study involved a total of 33,421 for the FQs group and 133,684 for the FQs free controls. Of the enrolled patients $(n=167,105)$, collagen-associate adverse effects developed in $85(0.051 \%)$ in 6-month tracking, including $0.051 \%$ in the FQs study cohort (17 in 33,421 ) and $0.051 \%$ (68 in 133,684) in the FQs-free comparison cohort.

\section{Baseline characteristics of patients}

Baseline characteristics of case patients and comparators are listed in the Table 1 . There were no significant differences between the FQs group and FQ-free group in the distributions of age and sex, but the proportion of catastrophic illness was slightly higher in the FQs group than the FQs-free groups (0.6 vs. 0.38).

\section{Collagen-associated adverse events}

In the cohort, we did not observe any case of tendons rupture, retinal detachments, aortic aneurysms, and aortic dissection. Patients with collagen-associated adverse events (GI perforation) in FQs group included 1 individual in 7-day tracking, 3 individuals in 14-days tracking, 4 individuals in 28-days tracking, 12 individuals in 3-month tracking, and 17 individuals in 6-month tracking. However, patients with collagen-associated adverse events (GI perforation) in FQs free group were 2 individuals in 3days tracking, 6 individuals in 7-days tracking, 10 individuals in 14-days tracking, 14 individuals in 28days tracking, 45 individuals in 3-month tracking, 68 individuals in 6-month tracking (Fig. 1). The crude HR for collagen-associated adverse events in FQs group was 0.997 (95\% CIs; 0.586-1.696; $p=0.990$ ) (Table 2).

\section{Risk of collagen-associated adverse events}

After adjusting for age, sex, catastrophic illness, lowincome household, seasons, levels of urbanization and healthcare, the adjusted HR for collagen-associated adverse events in FQs group was 1.330 (95\% CI; 0.7782.276; $p=0.255$ ). After multivariate analysis, we noticed that patient's age was associated with the risk of GI perforation. As shown in Table 2, the risk of collagenassociate adverse effect was lower in patients aged 5 9 years old $(\mathrm{aHR}=0.433 ; 95 \%$ CIs $=0.179-0.952 ; \quad p=$ $0.040)$, patients aged $10 \sim 14$ years old $(\mathrm{aHR}=0.386 ; 95 \%$ $\mathrm{CI}=0.163-0.909 ; p=0.028$ ).

\section{Subgroup analyses}

The association of FQs with subsequent GI perforation was stratified by baseline demographic, catastrophic illness, low- income household, seasons, levels of urbanization and healthcare. Analyses of factors of GI perforation in 6month tracking stratified by the aforementioned variables were performed by Cox regression as shown in Table 3 . We did not observe any statistically significant difference between FQs group and FQs-free group after subgroup analyses of gender, age, catastrophic illness, low-income household, seasons, levels of urbanization and healthcare.

\section{Stratified by fluoroquinolones}

Also, we did the subgroup analysis to confirm the association of FQs subgroup with subsequent GI perforation in different tracking periods by using Cox regression. In 3-day tracking period, we observed 2 events from FQsfree group. In 7-day tracking period, we observed 1 event from ofloxacin in the FQs group, and 6 events from $\mathrm{FQs}$-free group. In 14-day tracking period, we observed 1 event from ciprofloxacin, 1 event from norfloxacin, and 1 event from ofloxacin in the FQs group, and 10 events from FQs-free group. In 28-day tracking period, we observed 1 event from ciprofloxacin, 1 event from norfloxacin, 2 events from ofloxacin in the FQs group, and 14 events from FQs-free group. In 3-month tracking period, we observed 1 event from ciprofloxacin, 3 events from norfloxacin, and 8 events from ofloxacin in the FQs group, and 45 events from FQs-free group. In 6-month tracking period, we observed 1 event from ciprofloxacin, 3 events from norfloxacin, and 13 events from ofloxacin in the FQs group, and 68 events from FQs-free group. The incidence rate and adjusted HR are listed in Table 4. None of them were statistically significant difference between FQs group and FQs-free group.

\section{Discussion}

Fluoroquinolones are highly effective antimicrobial agents with the following advantages: a broad spectrum of bactericidal activity, ideal bioavailability, both oral and intravenous formulations, high serum levels and a large volume of distribution. These advantages increase the FQs usage in a wide variety of infectious diseases, including skin and respiratory infections for adults. However; the post-marketing surveillance data indicates that FQs may cause subsequent collagen-associated adverse events. Since year 2008, the U.S. FDA has declared several warnings about the association of FQs with disabling and potentially permanent side effects involving tendons, muscles, joints, nerves and the central nervous system in succession [28]. Additionally, due to the toxic effects observed from juvenile animals treated with FQs, the use of FQ-related drugs became rather limited in pediatric population [13]. Only ciprofloxacin and levofloxacin are approved by the U.S. FDA for the treatment of inhalation anthrax, complicated UTIs, and pyelonephritis in children 
Table 1 Characteristics of study

\begin{tabular}{|c|c|c|c|c|c|c|c|}
\hline \multirow{2}{*}{$\begin{array}{l}\text { Fluoroquinolones } \\
\text { Variables }\end{array}$} & \multicolumn{2}{|l|}{ Total } & \multicolumn{2}{|l|}{ With } & \multicolumn{2}{|l|}{ Without } & \multirow[t]{2}{*}{$P$} \\
\hline & $\mathrm{n}$ & $\%$ & $n$ & $\%$ & $n$ & $\%$ & \\
\hline Total & 167,105 & & 33,421 & 20.00 & 133,684 & 80.00 & \\
\hline Collagen-associated adverse events & & & & & & & 0.990 \\
\hline Without & 167,020 & 99.95 & 33,404 & 99.95 & 133,616 & 99.95 & \\
\hline With & 85 & 0.05 & 17 & 0.05 & 68 & 0.05 & \\
\hline Collagen-associated adverse events subgroups & & & & & & & 0.990 \\
\hline Without & 167,020 & 99.95 & 33,404 & 99.95 & 133,616 & 99.95 & \\
\hline Tendons rupture & 0 & 0.00 & 0 & 0.00 & 0 & 0.00 & \\
\hline Retinal detachments & 0 & 0.00 & 0 & 0.00 & 0 & 0.00 & \\
\hline Gastrointestinal perforation & 85 & 0.05 & 17 & 0.05 & 68 & 0.05 & \\
\hline Aortic dissection/Aortic aneurysm & 0 & 0.00 & 0 & 0.00 & 0 & 0.00 & \\
\hline Gender & & & & & & & 0.999 \\
\hline Male & 85,990 & 51.46 & 17,198 & 51.46 & 68,792 & 51.46 & \\
\hline Female & 81,115 & 48.54 & 16,223 & 48.54 & 64,892 & 48.54 & \\
\hline Age (years) & $9.78 \pm 5.58$ & & $9.83 \pm 5.35$ & & $9.77 \pm 5.63$ & & 0.079 \\
\hline Age group (years) & & & & & & & 0.999 \\
\hline$<1$ & 5100 & 3.05 & 1020 & 3.05 & 4080 & 3.05 & \\
\hline 1 & 7145 & 4.28 & 1429 & 4.28 & 5716 & 4.28 & \\
\hline 2 & 7970 & 4.77 & 1594 & 4.77 & 6376 & 4.77 & \\
\hline 3 & 9060 & 5.42 & 1812 & 5.42 & 7248 & 5.42 & \\
\hline 4 & 10,680 & 6.39 & 2136 & 6.39 & 8544 & 6.39 & \\
\hline $5-9$ & 46,670 & 27.93 & 9334 & 27.93 & 37,336 & 27.93 & \\
\hline $10-14$ & 42,785 & 25.60 & 8557 & 25.60 & 34,228 & 25.60 & \\
\hline$\geqq 15$ & 37,695 & 22.56 & 7539 & 22.56 & 30,156 & 22.56 & \\
\hline Catastrophic illness & & & & & & & $<0.001$ \\
\hline Without & 166,398 & 99.58 & 33,222 & 99.40 & 133,176 & 99.62 & \\
\hline With & 707 & 0.42 & 199 & 0.60 & 508 & 0.38 & \\
\hline Low-income household & & & & & & & $<0.001$ \\
\hline Without & 164,089 & 98.20 & 32,561 & 97.43 & 131,528 & 98.39 & \\
\hline With & 3016 & 1.80 & 860 & 2.57 & 2156 & 1.61 & \\
\hline Season & & & & & & & $<0.001$ \\
\hline Spring (Mar - May) & 43,867 & 26.25 & 8757 & 26.20 & 35,110 & 26.26 & \\
\hline Summer (Jun - Aug) & 42,836 & 25.63 & 8435 & 25.24 & 34,401 & 25.73 & \\
\hline Autumn (Sep - Nov) & 41,287 & 24.71 & 8289 & 24.80 & 32,998 & 24.68 & \\
\hline Winter (Dec - Feb) & 39,115 & 23.41 & 7940 & 23.76 & 31,175 & 23.32 & \\
\hline Urbanization level & & & & & & & $<0.001$ \\
\hline 1 (the highest) & 45,240 & 27.07 & 7343 & 21.97 & 37,897 & 28.35 & \\
\hline 2 & 62,222 & 37.24 & 11,929 & 35.69 & 50,293 & 37.62 & \\
\hline 3 & 27,980 & 16.74 & 6433 & 19.25 & 21,547 & 16.12 & \\
\hline 4 (the lowest) & 31,663 & 18.95 & 7716 & 23.09 & 23,947 & 17.91 & \\
\hline Level of care & & & & & & & $<0.001$ \\
\hline Hospital center & 7559 & 4.52 & 1268 & 3.79 & 6291 & 4.71 & \\
\hline Regional hospital & 11,858 & 7.10 & 1939 & 5.80 & 9919 & 7.42 & \\
\hline Local hospital & 8762 & 5.49 & 1588 & 4.94 & 7174 & 5.63 & \\
\hline
\end{tabular}


Table 1 Characteristics of study (Continued)

\begin{tabular}{|c|c|c|c|c|c|c|c|}
\hline \multirow{2}{*}{$\begin{array}{l}\text { Fluoroquinolones } \\
\text { Variables }\end{array}$} & \multicolumn{2}{|l|}{ Total } & \multicolumn{2}{|l|}{ With } & \multicolumn{2}{|l|}{ Without } & \multirow[t]{2}{*}{$P$} \\
\hline & $n$ & $\%$ & $n$ & $\%$ & $n$ & $\%$ & \\
\hline Physician clinics & 138,926 & 83.14 & 28,626 & 85.65 & 110,300 & 82.51 & \\
\hline \multicolumn{8}{|l|}{ Comorbidities } \\
\hline Cerebrovascular accident & 43 & 0.03 & 8 & 0.02 & 35 & 0.03 & 0.819 \\
\hline Diabetes mellitus & 84 & 0.05 & 18 & 0.05 & 66 & 0.05 & 0.743 \\
\hline Hypertension & 96 & 0.06 & 20 & 0.06 & 76 & 0.06 & 0.838 \\
\hline Hyperlipidemia & 74 & 0.04 & 15 & 0.04 & 59 & 0.04 & 0.954 \\
\hline \multicolumn{8}{|l|}{ Drugs } \\
\hline Non-steroidal anti-inflammatory drugs & 5008 & 3.00 & 1023 & 3.06 & 3985 & 2.98 & 0.443 \\
\hline Systemic steroid & 915 & 0.55 & 188 & 0.56 & 727 & 0.54 & 0.679 \\
\hline
\end{tabular}

$P$ : Chi-square / Fisher exact test on category variables and t-test on continue variables

aged 1 to 17 years old [15]. Furthermore, with the overuse of antimicrobial agents in clinical practice, the emergence of antibiotic resistant bacteria is rising in Taiwan [29]. To overcome the surge of drug resistant issues, the use of FQs is also increasing. To evaluate the safety issue of FQs, it is necessary for us to investigate serious collagenassociated adverse events in pediatric population.

The main findings of our study demonstrated that there was no difference in the risk of collagen-associated adverse events between FQs group and FQs-free group in pediatric population. By reviewing published studies $[3-7,18]$, we noticed that the reported higher risk of collagen-associate adverse effect in FQs-related cases were found in patients at the age of over 18 years old. However, most of these studies were designed in casecontrol studies and the subjects were patients older than 18 years old $[3-7,18]$. After comparing the difference between our findings and previous reported results, we made the following to several explanations:

(i) The study design: the subjects from case-control studies were identified by evaluating the outcome status at the outset of the investigation $[4,5,18]$. Enrolled cases with the outcome of interest are matched with a control group without it. The major and inevitable problems in case-control studies are the sampling bias, observation bias and recall bias. In contrast, cohort studies are usually used to confirm the disease incidence, causes, and prognosis. Cohort studies are often utilized for measuring events in chronological order and clarifying the relationship between cause and effect [30,31]. Consequently, we designed our study in the form of cohort study to assess the association between use of FQs and effect of collagen-associated adverse events. We believe that this cohort study provides more objective and reliable information than casecontrol studies. (ii) Dosage adjustment and rigorous monitoring in pediatric population: dosage of FQs is calculated and adjusted for by body weight in children before prescriptions. Maximum dosage limitation is advised by clinical guideline and FDA [15]. Meanwhile, healthcare providers usually follow the recommendation strictly because of the concern of the adverse effects to this vulnerable population. Furthermore, physicians tend to avoid this class of antimicrobial agents in clinical practice and preserve them as the final therapy for difficult and serious bacterial infections. Therefore, the side effects become much less as expected attributing to precise dosage and strict indication.

(iii) Comorbidity in elderly population: with regard to most of the FQs studies $[3-7,18]$, the enrolled subjects were older than 18 years old, especially the elderly population with comorbidities, like cardiovascular diseases and diabetes [32]. For example, cardiovascular diseases such as hypertension and hyperlipidemia, make the blood vessels more vulnerable and subsequently increase the risk of aortic aneurysms [33]. Patients with diabetes have more problematic blood vessels and retinopathy, which increases the risk of retinal detachments [34, 35]. Thus, these underlying diseases may contribute to the side effects of FQs to some extent in elderly population, but they are less frequent in younger generation. These observative findings may partially explain why we found that pediatric patients in our cohort have less side effects compared with previous reports. Since these comorbidities were adjusted as the covariates in our study, we believe that these items won't be the confounding factors in this cohort.

Though our findings differ from the previous studies, we believe that it reflects the real clinical situations in 
Table 2 Factors of gastrointestinal perforation in 6-month tracking by using Cox regression

\begin{tabular}{|c|c|c|c|c|c|c|c|c|c|c|c|c|}
\hline Variables & Crude HR & $95 \% \mathrm{Cl}$ & $95 \% \mathrm{Cl}$ & $P$ & Adjusted HR & $95 \% \mathrm{Cl}$ & $95 \% \mathrm{Cl}$ & $P$ & Adjusted HR & $95 \% \mathrm{Cl}$ & $95 \% \mathrm{Cl}$ & $P$ \\
\hline \multicolumn{13}{|l|}{ Fluoroquinolones } \\
\hline Without & Reference & & & & Reference & & & & Reference & & & \\
\hline With & 0.997 & 0.586 & 1.696 & 0.990 & 1.329 & 0.776 & 2.274 & 0.257 & 1.330 & 0.778 & 2.276 & 0.255 \\
\hline \multicolumn{13}{|l|}{ Gender } \\
\hline Male & 1.153 & 0.753 & 1.764 & 0.513 & 1.040 & 0.791 & 1.340 & 0.062 & 1.033 & 0.809 & 1.382 & 0.064 \\
\hline Female & Reference & & & & Reference & & & & Reference & & & \\
\hline Age (years) & 0.976 & 0.939 & 1.014 & 0.214 & 0.968 & 0.931 & 1.006 & 0.094 & & & & \\
\hline \multicolumn{13}{|l|}{ Age group (years) } \\
\hline$<1$ & Reference & & & & & & & & Reference & & & \\
\hline 1 & 1.835 & 0.708 & 4.756 & 0.212 & & & & & 2.047 & 0.784 & 5.345 & 0.123 \\
\hline 2 & 0.620 & 0.106 & 2.290 & 0.473 & & & & & 0.669 & 0.810 & 2.488 & 0.556 \\
\hline 3 & 1.802 & 0.715 & 4.540 & 0.212 & & & & & 1.822 & 0.752 & 4.648 & 0.189 \\
\hline 4 & 0.368 & 0.079 & 1.703 & 0.201 & & & & & 0.381 & 0.880 & 1.778 & 0.225 \\
\hline $5-9$ & 0.441 & 0.193 & 1.008 & 0.052 & & & & & 0.433 & 0.179 & 0.952 & 0.040 \\
\hline $10-14$ & 0.415 & 0.177 & 0.971 & 0.043 & & & & & 0.386 & 0.163 & 0.909 & 0.028 \\
\hline$\geqq 15$ & 0.944 & 0.442 & 2.014 & 0.881 & & & & & 0.831 & 0.384 & 1.789 & 0.661 \\
\hline \multicolumn{13}{|l|}{ Catastrophic illness } \\
\hline Without & Reference & & & & Reference & & & & Reference & & & \\
\hline With & 5.972 & 0.014 & 161.782 & 0.985 & 2.740 & 0.292 & 13.421 & 0.928 & 2.739 & 0.291 & 13.411 & 0.938 \\
\hline \multicolumn{13}{|l|}{ Low-income household } \\
\hline Without & Reference & & & & Reference & & & & Reference & & & \\
\hline With & 1.643 & 0.090 & 4.620 & 0.661 & 1.546 & 0.076 & 4.105 & 0.578 & 1.541 & 0.072 & 4.070 & 0.572 \\
\hline \multicolumn{13}{|l|}{ Season } \\
\hline Spring & Reference & & & & Reference & & & & Reference & & & \\
\hline Summer & 0.218 & 0.127 & 0.377 & $<0.001$ & 0.209 & 0.121 & 0.362 & $<0.001$ & 0.022 & 0.126 & 0.374 & $<0.001$ \\
\hline Autumn & 0.017 & 0.006 & 0.047 & $<0.001$ & 0.018 & 0.006 & 0.048 & $<0.001$ & 0.017 & 0.007 & 0.050 & $<0.001$ \\
\hline Winter & 0.056 & 0.032 & 0.098 & $<0.001$ & 0.057 & 0.032 & 0.099 & $<0.001$ & 0.057 & 0.032 & 0.100 & $<0.001$ \\
\hline \multicolumn{13}{|l|}{ Urbanization level } \\
\hline 1 (the highest) & 1.993 & 1.032 & 3.849 & 0.040 & 2.034 & 1.033 & 4.002 & 0.033 & 2.043 & 1.031 & 4.024 & 0.029 \\
\hline 2 & 0.596 & 0.276 & 1.288 & 0.188 & 0.526 & 0.239 & 1.144 & 0.115 & 0.527 & 0.242 & 1.146 & 0.116 \\
\hline 3 & 2.357 & 1.184 & 4.691 & 0.015 & 2.581 & 1.294 & 5.146 & 0.003 & 2.586 & 1.294 & 5.153 & 0.006 \\
\hline 4 (the lowest) & Reference & & & & Reference & & & & Reference & & & \\
\hline \multicolumn{13}{|l|}{ Level of care } \\
\hline Hospital center & 2.909 & 1.232 & 6.871 & 0.015 & 2.768 & 1.132 & 6.759 & 0.014 & 2.757 & 1.124 & 6.734 & 0.010 \\
\hline Regional hospital & 7.613 & 4.608 & 12.579 & $<0.001$ & 8.351 & 5.008 & 13.884 & $<0.001$ & 8.480 & 5.029 & 14.208 & $<0.001$ \\
\hline Local hospital & 6.213 & 3.425 & 11.269 & $<0.001$ & 5.304 & 2.911 & 9.672 & $<0.001$ & 5.222 & 2.864 & 9.526 & $<0.001$ \\
\hline Physician clinics & Reference & & & & Reference & & & & Reference & & & \\
\hline \multicolumn{13}{|l|}{ Comorbidities (No reference) } \\
\hline Cerebrovascular accident & 10.454 & 0.022 & 25.124 & 0.986 & 5.131 & 0.009 & 16.752 & 0.992 & 5.104 & 0.009 & 16.641 & 0.992 \\
\hline Diabetes mellitus & 3.401 & 0.564 & 6.785 & 0.298 & 3.105 & 0.482 & 6.131 & 0.384 & 3.078 & 0.476 & 6.079 & 0.390 \\
\hline Hypertension & 1.898 & 0.675 & 3.996 & 0.744 & 1.776 & 0.603 & 3.297 & 0.756 & 1.623 & 0.598 & 3.111 & 0.758 \\
\hline Hyperlipidemia & 0.000 & - & - & 0.989 & 0.000 & - & - & 0.997 & 0.000 & - & - & 0.997 \\
\hline \multicolumn{13}{|l|}{ Drugs (No reference) } \\
\hline NSAID & 1.264 & 0.842 & 1.677 & 0.562 & 1.189 & 0.675 & 1.597 & 0.599 & 1.187 & 0.673 & 1.589 & 0.598 \\
\hline Systemic steroid & 1.101 & 0.765 & 1.297 & 0.438 & 1.086 & 0.567 & 1.273 & 0.501 & 1.085 & 0.561 & 1.270 & 0.497 \\
\hline
\end{tabular}


Table 3 Factors of gastrointestinal perforation in 6-month tracking stratified by variables listed in the table by using Cox regression

\begin{tabular}{|c|c|c|c|c|c|c|c|c|c|c|c|}
\hline \multirow{2}{*}{$\begin{array}{l}\text { Fluoroquinolones } \\
\text { Stratified }\end{array}$} & \multicolumn{3}{|l|}{ With } & \multicolumn{3}{|c|}{ Without } & \multirow[t]{2}{*}{ Ratio } & \multicolumn{4}{|c|}{ With vs. Without } \\
\hline & Events & PDs & Rate (per $10^{5} \mathrm{PDs}$ ) & Events & PDs & Rate (per $10^{5} \mathrm{PDs}$ ) & & Adjusted HR & $95 \% \mathrm{Cl}$ & $95 \% \mathrm{Cl}$ & $P$ \\
\hline Total & 17 & $5,940,776.06$ & 0.29 & 68 & $23,707,602.75$ & 0.29 & 0.998 & 1.330 & 0.778 & 2.276 & 0.255 \\
\hline \multicolumn{12}{|l|}{ Gender } \\
\hline Male & 10 & $3,060,435.00$ & 0.33 & 31 & $12,297,000.62$ & 0.25 & 1.296 & 1.744 & 0.921 & 2.983 & 0.643 \\
\hline Female & 7 & $2,880,341.06$ & 0.24 & 37 & $11,410,602.12$ & 0.32 & 0.749 & 1.008 & 0.556 & 1.724 & 0.297 \\
\hline \multicolumn{12}{|l|}{ Age group (years) } \\
\hline$<1$ & 1 & $183,600.00$ & 0.54 & 4 & $820,422.12$ & 0.49 & 1.117 & 1.503 & 0.876 & 2.572 & 0.675 \\
\hline 1 & 2 & $256,265.94$ & 0.78 & 3 & $876,927.19$ & 0.34 & 2.281 & 2.279 & 0.998 & 4.027 & 0.052 \\
\hline 2 & 1 & $286,506.19$ & 0.35 & 4 & $1,024,530.50$ & 0.39 & 0.894 & 1.194 & 0.702 & 1.960 & 0.536 \\
\hline 3 & 2 & $325,930.75$ & 0.61 & 5 & $1,282,879.44$ & 0.39 & 1.574 & 1.822 & 0.943 & 2.894 & 0.071 \\
\hline 4 & 1 & $384,465.19$ & 0.26 & 6 & $1,542,322.12$ & 0.39 & 0.669 & 0.899 & 0.525 & 1.275 & 0.489 \\
\hline $5-9$ & 3 & $1,677,499.81$ & 0.18 & 14 & $6,622,008.94$ & 0.21 & 0.846 & 1.139 & 0.669 & 1.949 & 0.376 \\
\hline $10-14$ & 2 & $1,521,852.94$ & 0.13 & 10 & $6,123,547.69$ & 0.16 & 0.805 & 1.080 & 0.635 & 1.851 & 0.447 \\
\hline$\geqq 15$ & 5 & $1,304,655.25$ & 0.38 & 22 & $5,414,964.75$ & 0.41 & 0.943 & 1.271 & 0.742 & 2.170 & 0.285 \\
\hline \multicolumn{12}{|l|}{ Catastrophic illness } \\
\hline Without & 16 & $5,907,063.87$ & 0.27 & 68 & $23,616,531.12$ & 0.29 & 0.941 & 1.264 & 0.735 & 2.163 & 0.194 \\
\hline With & 1 & $33,712.19$ & 2.97 & 0 & $91,071.62$ & 0.00 & $\infty$ & $\infty$ & - & - & 0.796 \\
\hline \multicolumn{12}{|c|}{ Low-income household } \\
\hline Without & 16 & $5,789,090.44$ & 0.28 & 68 & $23,320,517.25$ & 0.29 & 0.948 & 1.277 & 0.744 & 2.183 & 0.182 \\
\hline With & 1 & $151,685.62$ & 0.66 & 0 & $387,085.50$ & 0.00 & $\infty$ & $\infty$ & - & - & 0.785 \\
\hline \multicolumn{12}{|l|}{ Season } \\
\hline Spring & 5 & $1,209,564.81$ & 0.41 & 23 & $6,731,139.19$ & 0.34 & 1.210 & 1.628 & 0.952 & 2.792 & 0.073 \\
\hline Summer & 3 & $1,211,624.37$ & 0.25 & 12 & $5,549,493.38$ & 0.22 & 1.145 & 1.539 & 0.901 & 2.639 & 0.102 \\
\hline Autumn & 2 & $1,596,290.69$ & 0.13 & 10 & $5,377,612.87$ & 0.19 & 0.674 & 0.907 & 0.524 & 1.551 & 0.773 \\
\hline Winter & 7 & $1,923,296.19$ & 0.36 & 23 & $6,049,357.31$ & 0.38 & 0.957 & 1.288 & 0.751 & 2.204 & 0.288 \\
\hline \multicolumn{12}{|l|}{ Urbanization level } \\
\hline 1 (the highest) & 6 & $1,305,977.19$ & 0.46 & 30 & $6,700,633.87$ & 0.45 & 1.026 & 1.378 & 0.808 & 2.364 & 0.134 \\
\hline 2 & 2 & $2,119,226.31$ & 0.09 & 12 & $8,911,079.56$ & 0.13 & 0.701 & 0.942 & 0.553 & 1.616 & 0.446 \\
\hline 3 & 7 & $1,142,905.31$ & 0.61 & 19 & $3,835,392.81$ & 0.50 & 1.236 & 1.663 & 0.971 & 2.843 & 0.059 \\
\hline 4 (the lowest) & 2 & $1,372,667.25$ & 0.15 & 7 & $4,260,496.50$ & 0.16 & 0.887 & 1.185 & 0.692 & 2.041 & 0.334 \\
\hline \multicolumn{12}{|l|}{ Level of care } \\
\hline Hospital center & 6 & $222,455.87$ & 2.70 & 26 & $1,083,958.87$ & 2.40 & 1.124 & 1.156 & 0.884 & 2.588 & 0.240 \\
\hline Regional hospital & 5 & $343,936.38$ & 1.45 & 19 & $1,737,590.94$ & 1.09 & 1.329 & 1.794 & 0.972 & 3.059 & 0.062 \\
\hline Local hospital & 4 & $281,046.94$ & 1.42 & 15 & $1,249,182.12$ & 1.20 & 1.185 & 1.589 & 0.932 & 2.735 & 0.179 \\
\hline Physician clinics & 2 & $5,093,336.87$ & 0.04 & 8 & $19,636,870.81$ & 0.04 & 0.964 & 1.290 & 0.759 & 2.214 & 0.304 \\
\hline
\end{tabular}

PDs Person-days, Adjusted HR Adjusted Hazard ratio: Adjusted for the variables listed in Table 2, Cl Confidence interval

pediatric population by meticulously analyzing the database resource in Taiwan. The National Health Insurance Research Database (NHIRD) of Taiwan, which covers more than $99.6 \%$ of the Taiwanese population, makes our study results more statistically powerful and representative [21]. NHIRD has been also widely used in generating evidences to support clinical decisions or healthcare policy-making [22].

Several limitations of the study should be noted. First, we are not sure about the compliance of the outpatient department patients because some of them may discontinue oral form of FQs abruptly [36]. It may cause underestimation of the adverse effects of FQs because the patients did not complete the treatment course. According to the results from previous studies, up to $52.7 \%$ of subjects reported that they did not precisely follow the physicians' advice about antibiotics use [37]. Second, the clinical conditions and underlying diseases of the enrolled cases during the observation period were not available. Underlying illness and chronic diseases may predispose to develop the collagen-associated adverse effects significantly. Third, no supportive image reports 
Table 4 Factors of gastrointestinal perforation stratified by fluoroquinolones subgroup in different tracking period by using Cox regression

\begin{tabular}{|c|c|c|c|c|c|c|c|c|c|c|c|c|c|}
\hline $\begin{array}{l}\text { Tracking } \\
\text { period }\end{array}$ & $\begin{array}{l}\text { Fluoroquinolones } \\
\text { subgroup }\end{array}$ & Populations & Events & PDs & Rate (per $10^{5} \mathrm{PDs}$ ) & Adjusted HR & $95 \% \mathrm{Cl}$ & $95 \% \mathrm{Cl}$ & $P$ & Adjusted HR & $95 \% \mathrm{Cl}$ & $95 \% \mathrm{Cl}$ & $P$ \\
\hline \multirow[t]{8}{*}{ 3-day } & Without & 133,684 & 2 & $23,707,602.75$ & 0.01 & Reference & & & & Reference & & & \\
\hline & With & 33,421 & 0 & $5,940,776.06$ & 0.00 & 0.000 & - & - & 0.995 & & & & \\
\hline & Levofloxacin & 653 & 0 & $112,735.69$ & 0.00 & & & & & 0.000 & - & - & 0.960 \\
\hline & Ciprofloxaxin & 1843 & 0 & $316,411.56$ & 0.00 & & & & & 0.000 & - & - & 0.978 \\
\hline & Moxifloxacin & 139 & 0 & $24,500.00$ & 0.00 & & & & & 0.000 & - & - & 0.988 \\
\hline & Gemifloxacin & 12 & 0 & 2160.00 & 0.00 & & & & & 0.000 & - & - & 0.998 \\
\hline & Norfloxacin & 7041 & 0 & $1,261,596.87$ & 0.00 & & & & & 0.000 & - & - & 0.996 \\
\hline & Ofloxacin & 23,733 & 0 & $4,223,371.94$ & 0.00 & & & & & 0.000 & - & - & 0.990 \\
\hline \multirow[t]{8}{*}{ 7-day } & Without & 133,684 & 6 & $23,707,602.75$ & 0.03 & Reference & & & & Reference & & & \\
\hline & With & 33,421 & 1 & $5,940,776.06$ & 0.02 & 0.512 & 0.080 & 27.426 & 0.756 & & & & \\
\hline & Levofloxacin & 653 & 0 & $112,735.69$ & 0.00 & & & & & 0.000 & - & - & 0.982 \\
\hline & Ciprofloxaxin & 1843 & 0 & $316,411.56$ & 0.00 & & & & & 0.000 & - & - & 0.979 \\
\hline & Moxifloxacin & 139 & 0 & $24,500.00$ & 0.00 & & & & & 0.000 & - & - & 0.993 \\
\hline & Gemifloxacin & 12 & 0 & 2160.00 & 0.00 & & & & & 0.000 & - & - & 0.986 \\
\hline & Norfloxacin & 7041 & 0 & $1,261,596.87$ & 0.00 & & & & & 0.000 & - & - & 0.978 \\
\hline & Ofloxacin & 23,733 & 1 & $4,223,371.94$ & 0.02 & & & & & 0.776 & 0.114 & 72.301 & 0.442 \\
\hline \multirow[t]{8}{*}{ 14-day } & Without & 133,684 & 10 & $23,707,602.75$ & 0.04 & Reference & & & & Reference & & & \\
\hline & With & 33,421 & 3 & $5,940,776.06$ & 0.05 & 1.025 & 0.044 & 1.356 & 0.111 & & & & \\
\hline & Levofloxacin & 653 & 0 & $112,735.69$ & 0.00 & & & & & 0.000 & - & - & 0.986 \\
\hline & Ciprofloxaxin & 1843 & 1 & $316,411.56$ & 0.32 & & & & & 1.572 & 0.052 & 7.166 & 0.678 \\
\hline & Moxifloxacin & 139 & 0 & $24,500.00$ & 0.00 & & & & & 0.000 & - & - & 0.995 \\
\hline & Gemifloxacin & 12 & 0 & 2160.00 & 0.00 & & & & & 0.000 & - & - & 0.986 \\
\hline & Norfloxacin & 7041 & 1 & $1,261,596.87$ & 0.08 & & & & & 1.342 & 0.020 & 6.988 & 0.501 \\
\hline & Ofloxacin & 23,733 & 1 & $4,223,371.94$ & 0.02 & & & & & 0.427 & 0.035 & 4.972 & 0.494 \\
\hline \multirow[t]{8}{*}{ 28-day } & Without & 133,684 & 14 & $23,707,602.75$ & 0.06 & Reference & & & & Reference & & & \\
\hline & With & 33,421 & 4 & $5,940,776.06$ & 0.07 & 1.137 & 0.090 & 1.498 & 0.157 & & & & \\
\hline & Levofloxacin & 653 & 0 & $112,735.69$ & 0.00 & & & & & 0.000 & - & - & 0.978 \\
\hline & Ciprofloxaxin & 1843 & 1 & $316,411.56$ & 0.32 & & & & & 1.266 & 0.028 & 2.999 & 0.267 \\
\hline & Moxifloxacin & 139 & 0 & $24,500.00$ & 0.00 & & & & & 0.000 & - & - & 0.978 \\
\hline & Gemifloxacin & 12 & 0 & 2160.00 & 0.00 & & & & & 0.000 & - & - & 0.964 \\
\hline & Norfloxacin & 7041 & 1 & $1,261,596.87$ & 0.08 & & & & & 2.052 & 0.184 & 22.485 & 0.532 \\
\hline & Ofloxacin & 23,733 & 2 & $4,223,371.94$ & 0.05 & & & & & 0.307 & 0.555 & 1.752 & 0.188 \\
\hline \multirow[t]{8}{*}{ 3-month } & Without & 133,684 & 45 & $23,707,602.75$ & 0.19 & Reference & & & & Reference & & & \\
\hline & With & 33,421 & 12 & $5,940,776.06$ & 0.20 & 1.049 & 0.156 & 1.925 & 0.198 & & & & \\
\hline & Levofloxacin & 653 & 0 & $112,735.69$ & 0.00 & & & & & 0.000 & - & - & 0.952 \\
\hline & Ciprofloxaxin & 1843 & 1 & $316,411.56$ & 0.32 & & & & & 1.076 & 0.013 & 1.972 & 0.129 \\
\hline & Moxifloxacin & 139 & 0 & $24,500.00$ & 0.00 & & & & & 0.000 & - & - & 0.978 \\
\hline & Gemifloxacin & 12 & 0 & 2160.00 & 0.00 & & & & & 0.000 & - & - & 0.986 \\
\hline & Norfloxacin & 7041 & 3 & $1,261,596.87$ & 0.24 & & & & & 1.472 & 0.402 & 5.411 & 0.524 \\
\hline & Ofloxacin & 23,733 & 8 & $4,223,371.94$ & 0.19 & & & & & 0.390 & 0.145 & 1.786 & 0.379 \\
\hline \multirow[t]{4}{*}{ 6-month } & Without & 133,684 & 68 & $23,707,602.75$ & 0.29 & Reference & & & & Reference & & & \\
\hline & With & 33,421 & 17 & $5,940,776.06$ & 0.29 & 1.330 & 0.778 & 2.276 & 0.255 & & & & \\
\hline & Levofloxacin & 653 & 0 & $112,735.69$ & 0.00 & & & & & 0.000 & - & - & 0.975 \\
\hline & Ciprofloxaxin & 1843 & 1 & $316,411.56$ & 0.32 & & & & & 1.402 & 0.197 & 10.121 & 0.702 \\
\hline
\end{tabular}


Table 4 Factors of gastrointestinal perforation stratified by fluoroquinolones subgroup in different tracking period by using Cox regression (Continued)

\begin{tabular}{|c|c|c|c|c|c|c|c|c|c|c|c|c|c|}
\hline $\begin{array}{l}\text { Tracking } \\
\text { period }\end{array}$ & $\begin{array}{l}\text { Fluoroquinolones } \\
\text { subgroup }\end{array}$ & Populations & Events & PDs & Rate (per $10^{5}$ PDs) & Adjusted HR & $95 \% \mathrm{Cl}$ & $95 \% \mathrm{Cl}$ & $P$ & Adjusted HR & $95 \% \mathrm{Cl}$ & $95 \% \mathrm{Cl}$ & P \\
\hline & Moxifloxacin & 139 & 0 & $24,500.00$ & 0.00 & & & & & 0.000 & - & - & 0.966 \\
\hline & Gemifloxacin & 12 & 0 & 2160.00 & 0.00 & & & & & 0.000 & - & - & 0.973 \\
\hline & Norfloxacin & 7041 & 3 & $1,261,596.87$ & 0.24 & & & & & 0.911 & 0.348 & 3.526 & 0.813 \\
\hline & Ofloxacin & 23,733 & 13 & $4,223,371.94$ & 0.31 & & & & & 1.442 & 0.793 & 2.601 & 0.199 \\
\hline
\end{tabular}

PDs Person-days, Adjusted HR Adjusted hazard ratio: Adjusted for the variables listed in Table 2, Cl Confidence interval

and laboratory data from each medical record to confirm the diagnosis of collagen-associated adverse effects, we defined the outcome in this study by reviewing the registration of ICD-9-CM codes. The potential misclassification bias cannot be ruled out in our study [38]. Despite the potential limits, our study also has some strengths because the results of this study are based on a realworld database analysis. The enormous number of prescriptions records makes the results more reliable and unbiased. In addition, we tracked the patient's outcome up to 6 months to see the long-term impact of the FQs exposure.

\section{Conclusions}

We designed this population-based, retrospective cohort study to evaluate the safety of FQs in pediatric population in Taiwan. In this study, we did not observe any statistically significant difference in the incidence of collagen-associated adverse events between FQs group and FQs-free group. FQs use in pediatric patients seems safe under instruction on the basis of our findings. Therefore, the risk of collagen-associated adverse events in pediatric population may be overestimated in previous studies. Since physicians still need FQs to treat serious and fulminant bacterial infections in children, our data supports that physicians may prescribe FQs in seriously infected young patients as indicated in the guideline.

\section{Abbreviations}

aHR: Adjusted hazard ratio; Cl: Confidence interval; FQ: Fluoroquinolones; HR: Hazard ratio; ICD-9-CM: International Classification of Diseases, Ninth Revision, Clinical Modification; NHI: National Health Insurance; NHIRD: National Health Insurance Research Database; PDs: Person-days

\section{Acknowledgements}

Not applicable.

\section{Authors' contributions}

$\mathrm{P}-\mathrm{HY}$ and $\mathrm{C}-\mathrm{FH}$ conceptualized and designed the study, drafted the initial manuscript, and reviewed and revised the manuscript. J-WL, C-HC, Y-CC and W-CC designed the data collection instruments, collected data, carried out the initial analyses, and reviewed and revised the manuscript. Y-CC, C-AS and W-CC conceptualized and designed the study, coordinated and supervised data collection, and critically reviewed the manuscript for important intellectual content. All authors approved the final manuscript as submitted and agree to be accountable for all aspects of the work.
Funding

This study was funded by Tri-Service General Hospital Research Foundation (TSGH-C108-003, TSGH-B-109010). The funder has no role in the design, concept, data collection and interpretation, analysis, drafting or other process in this paper.

Availability of data and materials

The data that support the findings of this study are available from Health and Welfare Data Science Center, Ministry of Health and Welfare (HWDC, MOHW) of Taiwan but restrictions apply to the availability of these data, which were used under license for the current study, and so are not publicly available.

\section{Ethics approval and consent to participate}

This study was conducted following the Code of Ethics of the World Medical Association (Declaration of Helsinki). The Institutional Review Board of Tri-Service General Hospital approved this study and waived the need for individual written informed consent because all participants' ID was removed or properly concealed (TSGH IRB No.2-105-05-082).

\section{Consent for publication}

Not applicable.

\section{Competing interests}

The authors declare that they have no competing interests.

\section{Author details}

${ }^{1}$ Master Program of Big Data in Biomedicine, College of Medicine, Fu Jen Catholic University, New Taipei City, Taiwan. ${ }^{2}$ Department of Pharmacy, Fu Jen Catholic University Hospital, Fu Jen Catholic University, New Taipei City, Taiwan. ${ }^{3}$ Department of Pediatrics, Tri-Service General Hospital, National Defense Medical Center, Taipei, Taiwan. ${ }^{4}$ School of Pharmacy, College of Pharmacy, Taipei Medical University, Taipei, Taiwan. ${ }^{5}$ School of Public Health, National Defense Medical Center, Taipei 11490, Taiwan. ${ }^{6}$ School of Medicine, College of Medicine, Fu Jen Catholic University, New Taipei, Taiwan. ${ }^{7}$ Big Data Research Center, College of Medicine, Fu Jen Catholic University, New Taipei City, Taiwan. ${ }^{8}$ Department of Public Health, College of Medicine, Fu Jen Catholic University, New Taipei City, Taiwan. ${ }^{9}$ Graduate Institute of Life Sciences, National Defense Medical Center, Taipei 11490, Taiwan.

${ }^{10}$ Department of Medical Research, Tri-Service General Hospital, National Defense Medical Center, No 325, Section 2, Cheng-Kung Road, Taipei 11490, Taiwan, Republic of China.

Received: 13 November 2019 Accepted: 6 February 2020

Published online: 11 February 2020

\section{References}

1. Lode H, Hoffken G, Boeckk M, Deppermann N, Borner K, Koeppe P. Quinolone pharmacokinetics and metabolism. J Antimicrob Chemother. 1990;26(Suppl B):41-9.

2. Mant TG. Multiple-dose pharmacokinetics of lomefloxacin: rationale for once-a-day dosing. Am J Med. 1992;92(4a):26s-32s.

3. Daneman N, Lu H, Redelmeier DA. Fluoroquinolones and collagen associated severe adverse events: a longitudinal cohort study. BMJ Open. 2015;5(11):e010077.

4. Hsu SC, Chang SS, Lee MG, Lee SH, Tsai YW, Lin SC, et al. Risk of gastrointestinal perforation in patients taking oral fluoroquinolone therapy: 
an analysis of nationally representative cohort. PLoS One. 2017;12(9): e0183813.

5. Etminan M, Forooghian F, Brophy JM, Bird ST, Maberley D. Oral fluoroquinolones and the risk of retinal detachment. JAMA. 2012;307(13):1414-9.

6. Stephenson AL, Wu W, Cortes D, Rochon PA. Tendon injury and fluoroquinolone use: a systematic review. Drug Saf. 2013;36(9):709-21.

7. Pasternak B, Inghammar M, Svanstrom H. Fluoroquinolone use and risk of aortic aneurysm and dissection: nationwide cohort study. BMJ. 2018;360:k678.

8. Sendzik J, Shakibaei M, Schafer-Korting M, Stahlmann R. Fluoroquinolones cause changes in extracellular matrix, signalling proteins, metalloproteinases and caspase-3 in cultured human tendon cells. Toxicology. 2005;212(1):24-36.

9. Sykes EM Jr. Colon perforation in Ehlers-Danlos syndrome. Report of two cases and review of the literature. Am J Surg. 1984;147(3):410-3.

10. Germain DP. Clinical and genetic features of vascular Ehlers-Danlos syndrome. Ann Vasc Surg. 2002;16(3):391-7.

11. Administration. USFaD. FDA warns about increased risk of ruptures or tears in the aorta blood vessel with fluoroquinolone antibiotics in certain patients. Available from: https://www.fda.gov/drugs/drug-safety-andavailability/fda-warns-about-increased-risk-ruptures-or-tears-aorta-bloodvessel-fluoroquinolone-antibiotics. Accessed 21 Dec 2018.

12. Administration. USFaD. FDA Drug Safety Communication: FDA updates warnings for oral and injectable fluoroquinolone antibiotics due to disabling side effects. Available from: https://www.fda.gov/drugs/drugsafety-and-availability/fda-drug-safety-communication-fda-updates-warningsoral-and-injectable-fluoroquinolone-antibiotics. Accessed 8 May 2018.

13. Jackson MA, Schutze GE. The use of systemic and topical fluoroquinolones. Pediatrics. 2016;138(5). https://doi.org/10.1542/peds.2016-2706.

14. Pediatric Infectious Diseases Society of Taiwan CHRC, National Health Research Institutes. Recommendations for the Use of New Quinolone Antibiotics in Children. Available from: http://www.pids.org.tw/index. php?route=news/news_detail\&news_id=91. Accessed 20 Feb 2012.

15. Patel K, Goldman JL. Safety concerns surrounding quinolone use in children. J Clin Pharmacol. 2016;56(9):1060-75.

16. Yi FH. The prescribing pattern of Fluoroquinolone in pediatric patients in Taiwan. Tainan City: National Cheng Kung University; 2013.

17. Pediatric Infectious Diseases Society of Taiwan CHRC, National Health Research Institutes. Recommendations for the diagnosis and management of acute otitis media in children. Available from: http://www.pids.org.tw/ index.php?route=news/news_detail\&news_id=96. Accessed 1 Oct 2016.

18. Lee CC, Lee MT, Chen YS, Lee SH, Chen YS, Chen SC, et al. Risk of aortic dissection and aortic aneurysm in patients taking oral fluoroquinolone. JAMA Intern Med. 2015:175(11):1839-47.

19. Dixit A, Karandikar MV, Jones S, Nakamura MM. Safety and tolerability of Moxifloxacin in children. J Pediatric Infect Dis Soc. 2018;7(3):e92-e101.

20. Choi S-H, Kim EY, Kim Y-J. Systemic use of fluoroquinolone in children Korean J Pediatr. 2013;56(5):196-201.

21. Lin L-Y, Warren-Gash C, Smeeth L, Chen P-C. Data resource profile: the National Health Insurance Research Database (NHIRD). Epidemiol Health. 2018:40:e2018062

22. Hsieh C-Y, Su C-C, Shao S-C, Sung S-F, Lin S-J, Kao Yang Y-H, et al. Taiwan's national health insurance research database: past and future. Clin Epidemiol. 2019;1:349-58.

23. Cardile S, Martinelli M, Barabino A, Gandullia P, Oliva S, Di Nardo G, et al. Italian survey on non-steroidal anti-inflammatory drugs and gastrointestinal bleeding in children. World J Gastroenterol. 2016;22(5):1877-83.

24. Narum S, Westergren T, Klemp M. Corticosteroids and risk of gastrointestinal bleeding: a systematic review and meta-analysis. BMJ Open. 2014;4(5):e004587.

25. Tekin K, Inanc M, Kurnaz E, Bayramoglu E, Aydemir E, Koc M, et al. Quantitative evaluation of early retinal changes in children with type diabetes mellitus without retinopathy. Clin Exp Optom. 2018;101(5):680-5.

26. Lurbe E. Hypertension and target organ damage in children and adolescents. J Hypertens. 2007;25(10):1998-2000

27. Leone O, Corsini A, Pacini D, Corti B, Lorenzini M, Laus V, et al. The complex interplay among atherosclerosis, inflammation, and degeneration in ascending thoracic aortic aneurysms. J Thorac Cardiovasc Surg. 2019. https://doi.org/10.1016/j.jtcvs.2019.08.108.

28. Administration. USFaD. FDA updates warnings for fluoroquinolone antibiotics. Available from: https://www.fda.gov/news-events/pressannouncements/fda-updates-warnings-fluoroquinolone-antibiotics. Accessed 15 Aug 2016.
29. Wu CT, Lee HY, Chen $\mathrm{CL}$, Tuan PL, Chiu CH. High prevalence and antimicrobial resistance of urinary tract infection isolates in febrile young children without localizing signs in Taiwan. J Microbiol Immunol Infect. 2016:49(2):243-8.

30. Mann CJ. Observational research methods. Research design II: cohort, cross sectional, and case-control studies. Emerg Med J. 2003;20(1):54-60.

31. Song JW, Chung KC. Observational studies: cohort and case-control studies. Plast Reconstr Surg. 2010;126(6):2234-42.

32. Lloyd-Jones DM, Larson MG, Beiser A, Levy D. Lifetime risk of developing coronary heart disease. Lancet. 1999;353(9147):89-92.

33. Sidloff D, Choke E, Stather P, Bown M, Thompson J, Sayers R. Mortality from thoracic aortic diseases and associations with cardiovascular risk factors. Circulation. 2014;130(25):2287-94.

34. Cheung N, Mitchell P, Wong TY. Diabetic retinopathy. Lancet. 2010; 376(9735):124-36

35. Marso SP, Hiatt WR. Peripheral arterial disease in patients with diabetes. J Am Coll Cardiol. 2006;47(5):921-9.

36. Kardas P. Noncompliance in current antibiotic practice. Infect Dis Clin Pract. 2006;14(4):S11-S4

37. Chen C, Chen YM, Hwang KL, Lin SJ, Yang CC, Tsay RW, et al. Behavior, attitudes and knowledge about antibiotic usage among residents of Changhua. Taiwan J Microbiol Immunol Infect. 2005:38(1):53-9.

38. Mazzali C, Duca P. Use of administrative data in healthcare research. Intern Emerg Med. 2015;10(4):517-24

\section{Publisher's Note}

Springer Nature remains neutral with regard to jurisdictional claims in published maps and institutional affiliations.

Ready to submit your research? Choose BMC and benefit from:

- fast, convenient online submission

- thorough peer review by experienced researchers in your field

- rapid publication on acceptance

- support for research data, including large and complex data types

- gold Open Access which fosters wider collaboration and increased citations

- maximum visibility for your research: over $100 \mathrm{M}$ website views per year

At BMC, research is always in progress.

Learn more biomedcentral.com/submissions 